CONCISE REPORT

\title{
Disease related use of the internet in chronically ill adults: current and expected use
} W G J M van Lankveld, A M Derks, F H J van den Hoogen

Objective: To determine discrepancies in patients' current use and expected future use of the internet for different functions.

Method: A short questionnaire was developed to assess patients' current use of the internet for three functions: "seeking information", "mutual support", and "care provider contact". This questionnaire was assessed online during 1 week. For each of the functions, scales were computed to assess frequency of use. The same items were used to assess patients' expected future use. Differences in scale score between current use and expected use were calculated to determine discrepancies.

Results: 220 patients completed the questionnaire. Patients are frequent users of the internet. The three functions are largely independent of each other and independent of the type of disease and demographics. Most often patient use the internet to find information about the disease or treatment. The discrepancy between current and expected use is largest for the function "care provider contact".

Conclusion: Based on these findings it seems that patients are most strongly interested in an increased possibility of using the internet to contact their healthcare providers.

$\mathrm{T}$ he internet is one of the most popular sources of health related information for both healthy and diseased people. ${ }^{12}$ Patients use the internet for different functions: email, surfing the web for medical and general information, entertainment, and contact with other patients. ${ }^{3-5}$ A recent study from Germany showed that most German patients with rheumatic diseases actively use the internet. ${ }^{6}$ Although the internet provides new opportunities to learn, inform and communicate, ${ }^{17}$ the effects of increased use of the internet by people with chronic diseases are as yet unclear. The explosive increase of internet use has also raised some concern. ${ }^{8}$ Patients may misinterpret information on the internet, and a large proportion of disease related internet pages are backed by commercial interests. ${ }^{9}{ }^{10}$ Furthermore, internet use may increase social isolation. ${ }^{11}$

However, in evaluating the effects of the internet a distinction should be made between the different functions of the internet. Internet users themselves are seldom asked which functions they use. Moreover, patients who are frequenting disease related pages of the internet are experts in determining which functions they would like to use more often when available. Therefore, this study aimed at determining the interrelation between different disease related functions of the internet for patients with chronic diseases and at determining which of these functions patients would like to use more frequently in the future if available.

\section{PATIENTS AND METHODS Patients}

In November 2003 a web based survey was held, targeting people with chronic diseases who are familiar with the internet. Visitors of three websites for people with chronic diseases were invited to participate. Two websites target patients with rheumatic diseases: http://www.RAwijzer.nl (accessed 21 September 2005) for patients with rheumatoid arthritis; http://www.Reumadorp.nl (accessed 21 September 2005) for patients with rheumatic diseases in general. The third website included in the study gives information surrounding the Dutch National Week for Chronic Diseased people, thus targeting people with chronic somatic diseases, in general. When entering one of these websites, a pop-up screen appeared asking the visitor to participate in a short study. Visitors could select a "yes" or "no" button. If the patient agreed to participate in the study, a web page containing the questionnaire was displayed. The questionnaire was online for 1 week. A recent study showed that internet based questionnaires are as valid as mailed questionnaires. ${ }^{12}$

\section{Questions}

Firstly, visitors were asked to provide information about demographic variables such as age, sex, education, and global type of chronic somatic disease (rheumatic condition, chronic heart, lung or endocrine diseases, or other somatic disease). Separate questions were used to determine the frequency of internet use (daily, a few times every week, once a week, once a month, a few times every year, seldom/never) and place of internet use (at home, work, library, friends/family).

On the next page, a questionnaire was presented assessing the current use of the internet. The items comprising the questionnaire were based on interviews with six patients, four of them representatives of the Dutch National Patient organisation. All six patients were participating in a project to develop a website to be used by patients. Based on these interviews it was concluded that patients use the internet for three different purposes: to seek general information about their disease or its treatment, to get specific information from their own healthcare providers, and to search for mutual social support. A number of items were written to describe the different functions. These items were corrected by eight patients randomly chosen from our outpatient clinic.

Patients were asked to indicate how often they made use of the internet for that specific function on a scale from 1 to 5 (never, seldom, sometimes, often, very often). After completing this questionnaire, a new page showed the same questionnaire with the question: How often do you think you want to use the internet in the future for the following purposes.

\section{Statistical analysis}

Differences between groups were tested using a $t$ test for independent samples or $\chi^{2}$ statistics when appropriate. For 
Table 1 Distribution of answers (\%) in current use of the internet

\begin{tabular}{llrrrr}
\hline & \multicolumn{5}{c}{ Frequency of answers* } \\
\cline { 2 - 6 } Answer & $\mathbf{1}$ & $\mathbf{2}$ & $\mathbf{3}$ & $\mathbf{4}$ & $\mathbf{5}$ \\
\hline 1. Seek information about disease and drugs & 15 & 13 & 23 & 27 & 20 \\
2. Seek information about healthcare providers & 14 & 19 & 37 & 20 & 9 \\
3. Seek information about hospitals & 17 & 20 & 30 & 22 & 10 \\
4. Seek information about waiting time & 34 & 28 & 21 & 10 & 6 \\
5. Seek information about patient organisations & 21 & 19 & 32 & 16 & 12 \\
6. Put questions to my medical specialist & 51 & 15 & 19 & 12 & 4 \\
7. Put questions to other healthcare providers & 60 & 18 & 14 & 5 & 3 \\
8. Get assistance in physical exercise & 73 & 14 & 7 & 3 & 3 \\
9. Get in contact with my specialist & 77 & 13 & 8 & 1 & 1 \\
10. Get in contact with my specialised nurse & 79 & 9 & 8 & 2 & 0 \\
11. Chat with other patients & 69 & 11 & 10 & 6 & 4 \\
12. Take part in discussion groups & 67 & 8 & 12 & 8 & 4 \\
13. Get patient support & 63 & 9 & 14 & 7 & 7 \\
\hline *1. never; 2, seldom; 3, sometimes; 4, often; 5, very oftenoften. & & & & & \\
\hline
\end{tabular}

each of the three functions of "frequency of internet use' average item scores for each of the scales were computed. Cronbach's $\alpha$ was computed as a measure of internal consistency. Pearson's correlations between the three scale scores were computed to determine their relative independence. In addition, a principal component analysis on all the questions was performed to confirm the relative independence of the three functions. Differences between average item scores for each function were tested using Friedman's test for related ordinal samples. The difference between current and expected use of the different internet functions was tested using $t$ test for paired samples. Significance levels were set at $\mathrm{p}=0.05$.

\section{RESULTS}

The questionnaire was completed by 220 patients. As might be expected, most patients indicated that they had a rheumatic condition $(n=147)$, and 73 patients that they had another chronic disease (15 chronic heart condition, 20 lung or endocrine diseases, 38 other somatic disease). The majority of patients were female $(67 \%)$, and the mean (SD) age was 45 (8.5) years. Seventy per cent of the patients used the internet daily, and 21 per cent several times every week. Access to the internet was achieved at home $(82 \%)$ or at work $(18 \%)$. Patients with rheumatic conditions did not differ in any of the demographics variables from the responders with other chronic conditions.

Table 1 shows the questionnaire as it was presented to the patients online, as well as the frequency of the answers, ranging from 1 (never) to 5 (very often).

For each of the three functions average item scores were computed. The three scales assessing distinct functions of internet use showed very good internal consistency: Cronbach's $\alpha$ of "seeking information" (items 1, 2, 3, 4, 5) was 0.75 , for "mutual support" (items 11, 12, 13) Cronbach's $\alpha$ was 0.80 , and for the scale "care provider contact" (items 6, $7,8,9,10)$ 0.78. Intercorrelation between scale scores was moderate, ranging from $r=0.28$ to $r=0.42$. Principal component analysis confirmed the independence of the three functions of internet use. The analysis distinguished between three components in accordance with the three functions measured, explaining $62 \%$ of the variance. Patients with rheumatic conditions did not differ for any of the functions from patients with other chronic conditions. Frequency of internet use for any of its functions was independent of sex, age, education, and frequency of internet use or location.

The internet is mostly used to search for information (mean (SD) item score $2.8(0.9)$ ). Looking for mutual support was a less common reason for using the internet (mean (SD) score $1.8(1.2))$, as was contacting the healthcare provider
(1.6 (0.6)). The observed difference in frequency of internet use for the three functions was significant $\left(\chi^{2}=205.737\right.$; $\mathrm{df}=2 ; \mathrm{p}<0.001)$.

Average item scores for expected future use of the functions "seeking information", "mutual support", and "care provider contact" increased by 0.79, 0.95, and 1.32, respectively (all three comparisons: $t$ test for pairwise comparisons, $\mathrm{p}<0.01)$. The observed differences in average item change were significant (Friedman's $\chi^{2}=31.758$; $\mathrm{df}=2$; $\mathrm{p}<0.000)$. Observed increase between current and expected use of the internet was most explicit for the function "care provider contact".

\section{DISCUSSION}

Results show that patients with chronic diseases use the internet for different functions, and these functions are relatively independent of each other. Patients with chronic rheumatic diseases use the internet in the same way as patients with other chronic conditions. Patients most often use the internet to search for general information about the disease and its treatment. Similar findings were reported in another study. ${ }^{6}$ The internet is used less frequently for "mutual support" and "care provider contact". The largest discrepancy between current use and expected use in the future was observed in the function "care provider contact": from the patients' perspective, an increase in contact with their healthcare provider via the internet appears to be highly desirable.

This study is limited because only patients familiar with the internet participated. These patients are unlikely to represent a random sample of all patients with chronic diseases. However, because these patients are frequent users of the internet, their opinion about its expected future use is based on their experience. Another limitation of the study is that no information is available about the time of web use of the study participants, and that not all possible functions of the internet were examined. By focusing this study on disease related use of the internet, some functions with potentially positive effects have not been considered. For instance, home shopping or home working are generally available functions of the internet that can be of considerable importance to individual patients. Furthermore, the internet can also be used to target specific patient groups at specific times. ${ }^{13}$ In addition, internet based patient education and support interventions can be highly effective. ${ }^{1}$ As these functions are not yet available in the Netherlands they could not be examined in this study.

None the less, these findings confirm the importance of the internet to the patient, and the patients' wishes to use the internet even more in the future. Because the internet is here 
to stay, increasing numbers of patients will use it to search for information. Healthcare providers should thus assist the patient in evaluating the quality of the information on web based health resources. ${ }^{2}$ Furthermore, new methods need to be developed to use the internet for communication between patients and their healthcare providers. Internet based patient education and support interventions tailored to the patients' needs may have additional value above current methods of communication.

\section{ACKNOWLEDGEMENTS}

This study was supported by grants from ZonMw Medical Science and the Dutch League against Rheumatism.

\section{Authors' affiliations}

W G J M van Lankveld, A M Derks, F H J van den Hoogen, Department of Rheumatology, Sint Maartenskliniek, Nijmegen, The Netherlands

Correspondence to: Dr W G J M van Lankveld, Department of Rheumatology, Sint Maartenskliniek, PO Box 9011, 6500 GM Nijmegen, The Netherlands; w.vanlankveld@maartenskliniek.nl

Accepted 15 May 2005

Published Online First 26 May 2005

\section{REFERENCES}

1 Nguyen HQ, Carreiri-Kohlman V, Rankin SH, Slaughter R, Stulbarg MS. Internet-based patient education and support interventions: a review of evaluation studies and directions for future research. Comput Biol Med 2004;34:95-112.

2 Diaz JA, Griffith RA, Ng JJ, Reinert SE, Friedmann PD, Moulton AW. Patients' use of the internet for medical information. J Gen Intern Med 2002;17:180-5.

3 Drainoni M, Houlihan B, Williams S, Vedrani M, Esch D, Lee-Hood E, et al. Patterns of internet use by persons with spinal cord injuries and relationship to health-related quality of life. Arch Phys Rehabil 2004:85:1872-9.

4 National Research Council. Networking Health: prescriptions for the internet. Washington DC, USA: National Academy Press, 2000.

5 Cain MM, Mittman R, Sarasohn-Kahn J, Wayne JC. Health e-people: the online consumer experience. Institute for the future. Oakland USA: California Health Care Foundation, 2000.

6 Richter JG, Becker A, Specker C, Monser R, Schneider M. Krankheitsbezogene Internetnutzung bei Patienten met entzundlichrheumatischen Systemerkrankungen. Z Rheumatol 2004;64:216-22.

7 Wilson AS, Kitas GD, Llewellyn P, Carruthers DM, Cheseldine DC, Harris S, et al. Provision of internet-based rheumatology education. Rheumatology (Oxford) $2001 ; 40: 645-51$.

8 Edworthy SM. Crawling through the web: what do our patients find? J Rheumatol 2001;28:1-2.

9 Kim HA, Bae YD, Seo YI. Arthritis information on the web and its influence on patients and physicians: a Korean study. Clin Exp Rheumatol 2004;22:49-54.

10 Suarez-Almazor ME, Kendall CJ, Dorgan M. Surfing the Net-information on the World Wide Web for persons with arthritis: patient empowerment or patient deceit? J Rheumatol 2001;28:185-91.

11 Kraut R, Patterson M, Lundmark V, Kiesler S, Mukopadhyay T, Scherlis W. Internet paradox. A social technology that reduces social involvement and psychological well-being? Am Psychol 1998;53:1017-31.

12 Ritter P, Lorig K, Laurent D, Matthews K. Internet versus mailed questionnaires: a randomized comparison. J Med Internet Res 2004;15:e29.

13 Revere D, Dunbar PJ. Review of computer-generated outpatient health behaviour interventions: clinical encounters "in absentia". J Am Med Inform Assoc 2001;8:62-79. 